\title{
RESEARCH
}

Open Access

\section{High level of resistance in the mosquito Anopheles gambiae to pyrethroid insecticides and reduced susceptibility to bendiocarb in north-western Tanzania}

Natacha Protopopoff ${ }^{*}$, Johnson Matowo ${ }^{2}$, Robert Malima ${ }^{3}$, Reginald Kavishe ${ }^{2}$, Robert Kaaya ${ }^{2}$, Alexandra Wright ${ }^{1}$, Philippa A West ${ }^{4}$, Immo Kleinschmidt $^{5}$, William Kisinza ${ }^{3}$, Franklin W Mosha ${ }^{2}$ and Mark Rowland ${ }^{1}$

\begin{abstract}
Background: To control malaria in Tanzania, two primary vector control interventions are being scaled up: longlasting insecticide-treated nets (LLINs) and indoor residual spraying (IRS). The main threat to effective malaria control is the selection of insecticide resistance. While resistance to pyrethroids, the primary insecticide used for LLINs and IRS, has been reported among mosquito vectors in only a few sites in Tanzania, neighbouring East African countries are recording increasing levels of resistance. To monitor the rapidly evolving situation, the resistance status of the malaria vector Anopheles gambiae s.I to different insecticides and the prevalence of the $k d r$ resistance allele involved in pyrethroid resistance were investigated in north-western Tanzania, an area that has been subject to several rounds of pyrethroid IRS since 2006.

Methods: Household collections of anopheline mosquitoes were exposed to diagnostic dosages of pyrethroid, DDT, and bendiocarb using WHO resistance test kits. The relative proportions of An. gambiae s.s and Anopheles arabiensis were also investigated among mosquitoes sampled using indoor CDC light traps. Anophelines were identified to species and the $k d r$ mutation was detected using real time PCR TaqMan assays.

Results: From the light trap collections $80 \%$ of An. gambiae s.I were identified as An. gambiae s.s and $20 \%$ as An. arabiensis. There was cross-resistance between pyrethroids and DDT with mortality no higher than $40 \%$ reported in any of the resistance tests. The kdr-eastern variant was present in homozygous form in $97 \%$ of An. gambiae s.s but was absent in An. arabiensis. Anopheles gambiae s.s showed reduced susceptibility to the carbamate insecticide, bendiocarb, the proportion surviving WHO tests ranging from 0\% to 30\% depending on season and location.

Conclusion: Anopheles gambiae s.s has developed phenotypic resistance to pyrethroids and DDT and kdr frequency has almost reached fixation. Unlike in coastal Tanzania, where the ratio of An. gambiae s.s to An. arabiensis has decreased in response to vector control, An. gambiae s.s persists at high frequency in north-western Tanzania, probably due to selection of pyrethroid resistance, and this trend is likely to arise in other areas as resistance spreads or is subject to local selection from IRS or LLINs.
\end{abstract}

Keywords: Insecticide resistance, Knock down mutation, Anopheles arabiensis, Anopheles gambiae, Tanzania, Pyrethroid, Bendiocarb, Indoor residual spraying, Long-lasting insecticidal net

\footnotetext{
* Correspondence: natacha.protopopoff@lshtm.ac.uk

'Department of Disease Control, London School of Hygiene and Tropical Medicine, Keppel Street, London WC1E 7HT, UK

Full list of author information is available at the end of the article
} 


\section{Background}

Strong commitment from international agencies and home governments to reduce the burden of malaria in sub-Saharan Africa has led to a major scale-up of vector control measures and increased access to effective antimalarial treatment, and it is reported that malaria is on the wane in several African countries [1]. However a major menace is threatening the present achievements. Resistance to pyrethroid insecticide is spreading rapidly across Africa and could reduce the impact of our two most successful malaria prevention interventions - indoor residual spraying (IRS) and long-lasting insecticidal nets (LLINs) [2-4]. The two main mechanisms responsible for pyrethroid resistance are target site insensitivity, known as knock down resistance $k d r$, and metabolic resistance due to elevated levels of detoxifying enzymes [2]. $K d r$ is caused by mutations to the sodium channel, a leucine to phenylalanine change first observed in West Africa [5] and a leucine to serine mutation observed in East Africa [6]. Recently a new mutation in the sodium channel conferring additional resistance to DDT and permethrin as been reported associated with the $k d r$ west mutation [7].

To reduce the malaria burden in Tanzania, the National Malaria Control Programme (NMCP) is increasing the coverage of LLINs and IRS. Over the last 10 years LLINs have been distributed initially by targeting the most vulnerable groups, pregnant women and children aged under five, through discounted vouchers issued at antenatal clinics [8], and then by a national, free LLIN distribution campaign in 2010 [9] which was extended to the general population though a universal coverage LLIN distribution campaign in 2011. IRS with pyrethroid was initiated in Kagera region, situated on the western shore of Lake Victoria, in 2006 with support from the President's Malaria Initiative and extended to all Lake Zone in 2011.

Previous surveys conducted in Tanzania showed little or no resistance to DDT and pyrethroids in the Anopheles gambiae s.l population [10-12]. A study carried out in 2009/2010 showed no resistance to deltamethrin and DDT in Muleba [10], north-western district of Tanzania, where the present study is conducted. In this paper, the insecticide resistance status of the malaria vectors $A n$. gambiae s.s and Anopheles arabiensis to insecticides in use for IRS (lambdacyhalothrin and bendiocarb) and LLIN (permethrin and deltamethrin) is presented. The prevalence of the $k d r$ mutation was also investigated.

\section{Methods}

\section{Study area}

The study was carried out in Muleba district $\left(1^{\circ} 45^{\prime} \mathrm{S}\right.$, $31^{\circ} 40^{\prime} \mathrm{E}$ ) in Kagera region of north-western Tanzania on the western shore of Lake Victoria (Figure 1) as a component of a cluster randomized trial investigating the combined use of IRS and LLINS for malaria prevention (clinical trials identifier \# NCT01697852).

The study area is situated at 1,100-1,600 $\mathrm{m}$ above sea level. Since 2006 five rounds of IRS with the pyrethroid lambdacyhalothrin (ICON 10CS, Syngenta, Basel, Switzerland) were conducted in Muleba district. Since the present study was completed, two rounds of IRS have been carried out with the carbamate bendiocarb (FICAM 80\% Wettable Power, Bayer) in December 2011 and May 2012. Net coverage has increased since 2005 through net distribution campaigns initially targeting pregnant women and children aged under five in 2009 (63\% of households provided with nets) and then targeting the entire population at risk in 2011 (91\% household ownership) [13].

\section{Mosquito collection}

Monthly rounds of mosquito collections were carried out in 40 villages (Figure 1) from April to December 2011 using CDC light traps. During each monthly round of mosquito collecting, light trapping was conducted for one night in eight households selected at random from each village. Light traps were installed at the foot of human occupied beds covered with a treated or untreated bed net. Each of the villages had been subjected to an earlier round of pyrethroid IRS in January-February 2011.

Adult Anopheles were collected for WHO insecticide susceptibility testing in April-June and NovemberDecember 2011 in 11 villages by means of morning indoor resting catches using suction tubes. The collections were identified to species using a simplified morphological key adapted from Gillies and Coetzee [14] and stored individually for molecular identification and detection of $k d r$ variants.

\section{WHO insecticide resistance tests}

The collections of adult $A n$. gambiae s.l were tested in standard WHO resistance test kit using discriminating dosages of the pyrethroids lambdacyhalothrin (0.05\%), permethrin $(0.75 \%)$ and deltamethrin $(0.05 \%)$ and with DDT (4\%) and bendiocarb (0.1\%) [15]. WHO test and control papers were supplied by the WHO Collaborating Centre at Universiti Sains Malaysia, Penang, Malaysia. Test papers were used no more than five times before being replaced. Anopheline mosquitoes were exposed to the insecticides for one hour and mortality was scored after a 24-hour holding period [15] during which the Anopheles had access to sugar solution. Tests were excluded if control mortality exceeded 5\%. Physiological/ gonotrophic status was recorded. Tests with the same impregnated papers were performed against the $A n$. 
gambiae s.s Kisumu susceptible strain as a check on the quality of the test papers.

\section{Mosquito species identification and genotyping for $k d r$ mutations}

Genomic DNA was extracted from body parts (leg, antenna or wings) of An. gambiae s.l and was stored at $-20^{\circ} \mathrm{C}$ until use. Real time PCR using TaqMan assays was used to distinguish between the two sibling species
An. gambiae s.s and An arabiensis [16] and to distinguish between $k d r$ east and $k d r$ west genotypes $(k d r-w$ or $k d r-e)$ [17]. Genotyping results were analysed using MXPro software (Agilent technologies, Stratagene, USA).

\section{Data analysis}

Percentage mortality and 95\% confidence interval in WHO susceptibility tests was calculated by the binomial exact method using Stata 11 (Stata-Corporation, USA).

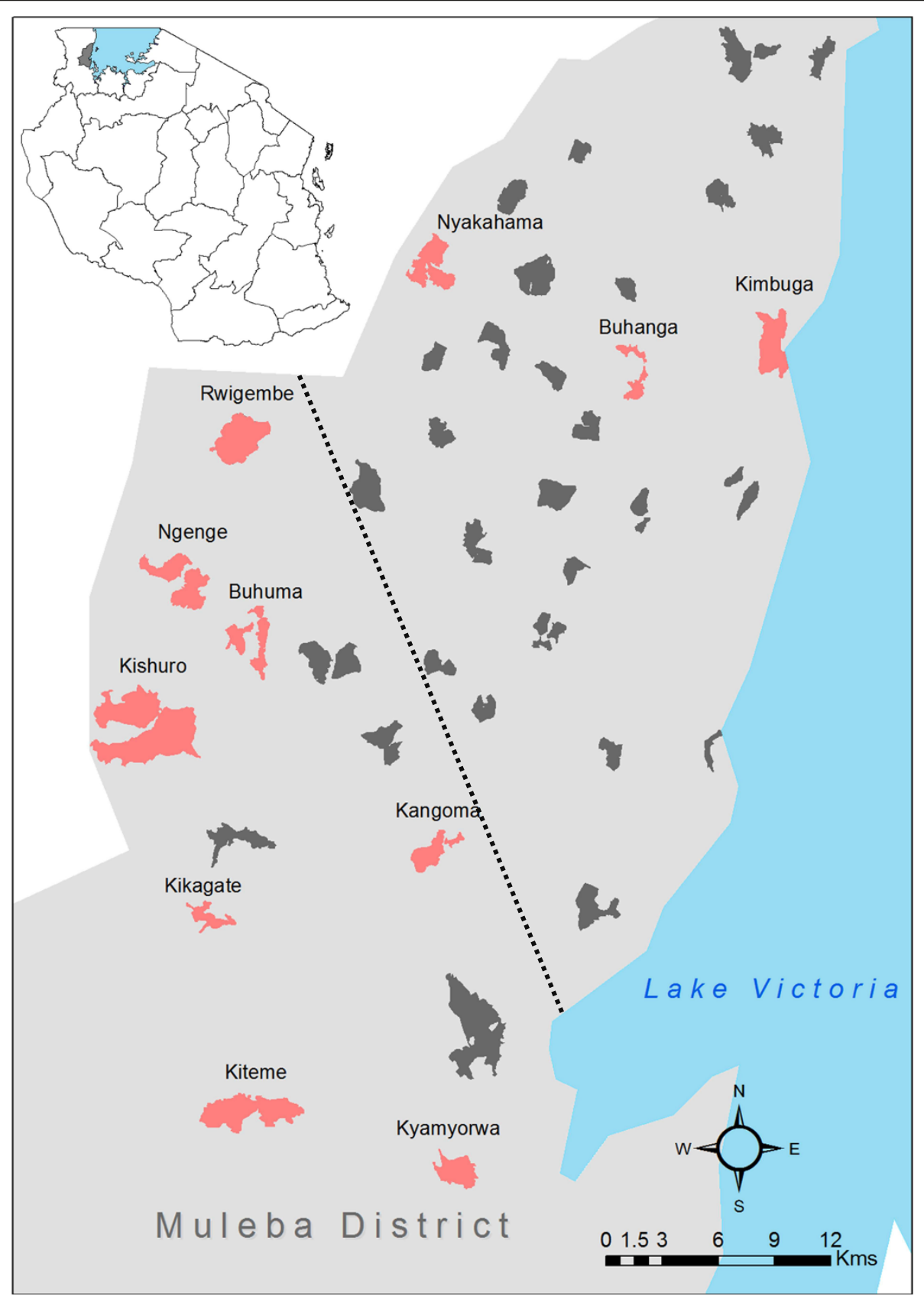

Figure 1 Map of Tanzania showing the study area (top left). Map showing villages where sampling was conducted. Sites, for morning resting collection to perform WHO resistance test and light trap collection, are shown in red. Sites where only light trap collection was done are in dark grey. The dotted line delimited the high density of Anopheles area in the south west from the low Anopheles density area in the north east. 
Regardless of the total number of An. gambiae s.l collected in light traps from a given cluster, the maximum subsample tested was limited to 50 individuals. The proportions of An. gambiae and An. arabiensis were determined in each subsample and weighted by the inverse of the sampling fraction (ie, subsample/total collected) to represent the relative proportion in the total population. Analysis of the difference in proportion of An. arabiensis and fed Anopheles between tests and months was done using logistic regression. $K d r$ genotype frequencies among dead and alive An. gambiae s.l in WHO tests and light trap collections across different rounds and clusters were compared using the software Genepop (version 4.0) [18]. The study map was designed using ArcGIS 10 (ESRI Japan Corp, Tokyo, Japan.).

\section{Ethics statement}

The trial was approved by the ethics review committees of the Kilimanjaro Christian Medical College, the National Institute for Medical Research Tanzania and the London School of Hygiene and Tropical Medicine (application no. 5814). Written informed consent was obtained from adults of each house where collections were made.

\section{Results}

\section{Light trap collection}

Seven rounds of light trap collection were completed in the 40 villages between April and December 2011 and a total of 5,762 An. gambiae s.l females were caught. The majority of mosquitoes (92\%) were collected from 13 villages situated in the south-west of the district (Figure 1).
A subsample of 2,346 was identified to species. The weighted proportion showed a ratio of $80 \%(95 \% \mathrm{CI}$ : 75\%-84\%) An. gambiae s.s to 20\% (95\% CI: $16 \%-25 \%$ ) An.arabiensis.

\section{WHO resistance tests}

Anopheles gambiae s.s accounted for $96.0 \%$ and $A n$. arabiensis for $3.7 \%$ of the An. gambiae s.l tested for resistance $(\mathrm{N}=901)$. Anopheles arabiensis was detected only in four sites, and made up $7.2 \%$ of An. gambiae s.l in Kishuro and 3.4\% in Kikagate in surveys done in May, and $2.6 \%$ in Kyamorwa and $18.2 \%$ in Kiteme in the surveys done in November. All 100\% An. arabiensis were killed in tests with, lambdacyhalothrin $(\mathrm{n}=11)$, deltamethrin $(\mathrm{n}=2)$, DDT $(\mathrm{n}=10)$ and bendiocarb $(\mathrm{n}=2)$, and $50 \%(4 / 8)$ in tests with the pyrethroid permethrin.

Anopheles gambiae s.s mortality to lambdacyhalothin $0.05 \%$ test papers ranged from $8 \%$ to $40 \%$ (Table 1 ) across the 11 villages sampled, indicating a high frequency of resistance in the area and some variation in resistance frequency by cluster. Mosquitoes tested in two villages, Kyarmorwa and Kikagate, showed a reduction in percentage mortality between May and November 2011 (from 34\% to $8 \%$ in Kyarmorwa and from $40 \%$ to $26 \%$ in Kikagate). The resistance to lambdacyhalothrin extended to permethrin and deltamethrin (Table 2) and also showed crossresistance to DDT with mortality ranging from $13 \%$ to $40 \%$ between villages. Similar temporal trends between surveys were observed to DDT as to lambdacyhothrin, indicating cross-resistance between DDT and pyrethroids.

Anopheles gambiae s.s showed reduced susceptibility to the carbamate bendiocarb in WHO resistance tests.

Table 1 Mortality rates ( $95 \%$ confidence interval) and blood-feeding status of Anopheles gambiae s.I from various localities exposed to lambdacyhalothrin $0.05 \%$ in WHO resistance tests

\begin{tabular}{|c|c|c|c|c|c|c|c|}
\hline \multirow{2}{*}{$\begin{array}{l}\text { Date of testing } \\
\text { May } 2011\end{array}$} & \multirow{2}{*}{$\begin{array}{l}\text { Village } \\
\text { Kikagate }\end{array}$} & \multirow{2}{*}{$\begin{array}{l}\text { Total tested } \\
35\end{array}$} & \multirow{2}{*}{$\begin{array}{l}\text { Replicate no. } \\
2\end{array}$} & \multicolumn{2}{|c|}{$\%$ mortality $(95 \% \mathrm{Cl})$} & \multirow{2}{*}{$\begin{array}{l}\% \text { blood-fed Anopheles } \\
100 \%\end{array}$} & \multirow{2}{*}{$\begin{array}{l}\boldsymbol{K} d \boldsymbol{r} \text { allele frequency } \\
95 \%\end{array}$} \\
\hline & & & & $34 \%$ & $(19-52)$ & & \\
\hline & Kyamyorwa & 230 & 12 & $40 \%^{3}$ & $(33-46)$ & $70 \%$ & $100 \%$ \\
\hline \multirow[t]{12}{*}{ Nov 2011} & Kishuro & 40 & 2 & $13 \%$ & $(4-27)$ & $24 \%$ & $99 \%$ \\
\hline & Ngenge & 52 & 3 & $25 \%$ & $(14-39)$ & $59 \%$ & $99 \%$ \\
\hline & Rwigembe & 42 & 2 & $31 \%$ & $(18-47)$ & $84 \%$ & $100 \%$ \\
\hline & Buhuma & 30 & 2 & $17 \%$ & $(6-35)$ & $78 \%$ & $100 \%$ \\
\hline & Kangoma & 105 & 6 & $8 \%^{1}$ & $(3-14)$ & $40 \%$ & $96 \%$ \\
\hline & Kikagate & 142 & 7 & $8 \%$ & $(4-14)$ & $74 \%$ & $98 \%$ \\
\hline & Kiteme & 104 & 6 & $31 \%^{2}$ & $(22-41)$ & $92 \%$ & $99 \%$ \\
\hline & Kyamyorwa & 149 & 7 & $26 \%^{3}$ & $(19-34)$ & $75 \%$ & $98 \%$ \\
\hline & Nyakahama & 13 & 1 & $38 \%$ & $(14-68)$ & $77 \%$ & $100 \%$ \\
\hline & Buhanga & 36 & 2 & $22 \%^{3}$ & $(10-39)$ & $86 \%$ & $98 \%$ \\
\hline & Kimbuga & 21 & 2 & $0 \%$ & $(0-16)$ & $43 \%$ & $94 \%$ \\
\hline & Kisumu strain & 100 & 4 & $100 \%$ & $(96-100)$ & & \\
\hline
\end{tabular}


Table 2 Mortality rates of the Anopheles gambiae s.I field populations from various localities exposed to deltamethrin, permethrin, DDT and bendiocarb

\begin{tabular}{|c|c|c|c|c|c|c|c|}
\hline \multirow{2}{*}{$\frac{\text { Insecticide }}{\text { Bendiocarb }(0.1 \%)}$} & \multirow{2}{*}{$\begin{array}{l}\text { Date } \\
\text { May } 2011\end{array}$} & \multirow{2}{*}{$\begin{array}{l}\text { Village } \\
\text { Kyamyorwa }\end{array}$} & \multirow{2}{*}{$\begin{array}{l}\text { Total tested } \\
112\end{array}$} & \multirow{2}{*}{$\begin{array}{l}\text { No. of replicates } \\
6\end{array}$} & \multicolumn{2}{|c|}{$\%$ mortality $(95 \% \mathrm{Cl})$} & \multirow{2}{*}{$\begin{array}{l}\text { \% blood-fed Anophele } \\
100 \%\end{array}$} \\
\hline & & & & & $100 \%$ & $(97-100)$ & \\
\hline & Nov 2011 & Kyamyorwa & 106 & 7 & $84 \%^{1}$ & $(76-90)$ & $78 \%$ \\
\hline & & Kangoma & 54 & 3 & $70 \%^{3}$ & $(56-82)$ & $86 \%$ \\
\hline & & Kikagate & 100 & 5 & $86 \%$ & $(78-92)$ & $65 \%$ \\
\hline & & Kiteme & 84 & 5 & $90 \%^{2}$ & $(82-96)$ & $96 \%$ \\
\hline & & Kisumu strain & 61 & 4 & $97 \%$ & $(89-100)$ & \\
\hline \multirow[t]{7}{*}{ DDT (4\%) } & May 2011 & Kyamyorwa & 98 & 5 & $37 \%$ & $(27-47)$ & $100 \%$ \\
\hline & Nov 2011 & Kyamyorwa & 99 & 5 & $13 \%^{1}$ & $(7-21)$ & $88 \%$ \\
\hline & & Rwigembe & 8 & 1 & $13 \%$ & $(0-53)$ & $36 \%$ \\
\hline & & Buhuma & 12 & 1 & $17 \%$ & $(2-48)$ & $58 \%$ \\
\hline & & Kikagate & 20 & 1 & $35 \%$ & $(15-59)$ & $55 \%$ \\
\hline & & Kiteme & 85 & 4 & $40 \%^{2}$ & $(30-51)$ & $100 \%$ \\
\hline & & Kisumu strain & 100 & 4 & $100 \%$ & $(96-100)$ & \\
\hline \multirow[t]{2}{*}{ Deltamethrin $(0.05 \%)$} & May 2011 & Kishuro & 20 & 1 & $70 \%$ & $(46-88)$ & $100 \%$ \\
\hline & & Kyamyorwa & 106 & 5 & $28 \%^{3}$ & $(20-38)$ & $100 \%$ \\
\hline Permethrin (0.75\%) & Nov 2011 & Kiteme & 98 & 5 & $11 \%$ & $(6-19)$ & $98 \%$ \\
\hline
\end{tabular}

Proportion of blood-fed Anopheles at the time of the testing is reported.

${ }^{1}$ Control mortality was $2 \%,{ }^{2} 3 \%$ and ${ }^{3} 4 \%$ in the test indicated with a subscript and was $0 \%$ in all the other test.

Percentage mortality in the village Kyarmorwa was $100 \%$ in May 2011 and 84\% in November 2011. Tests, done in other villages in November, produced mortality rates ranging from $70 \%$ to $90 \%$. Checks done on the $A n$. gambiae Kisumu susceptible strain produced $100 \%$ mortality on DDT and lambdacyhalothrin and 97\% mortality with the bendiocarb test papers.

Of the $A n$. gambiae collected for testing, 79\% were blood-fed, $14 \%$ were unfed and the remaining were gravid or semi-gravid (Table 1). There were variations in blood-feeding rates between the tests, however no differences in frequency of fed mosquitoes were observed in alive and dead mosquitoes exposed to lambdacyhalothrin $(\mathrm{p}=0.15)$.

\section{Kdr mutation}

Of the 2,049 An. gambiae s.s collected by light trap and tested for the $k d r$ east allele, 96.8\% $(\mathrm{n}=1,983)$ were homozygous for $k d r, 3 \%(\mathrm{n}=62)$ were heterozygous and only $0.2 \%(n=4)$ were homozygous for the susceptible type. All $A n$. arabiensis tested $(\mathrm{N}=297)$ were homozygous for susceptible type. There was no significant difference in genotype frequency in $A n$. gambiae s.s between collection rounds (Chi2 $=1.2, \mathrm{df}=2, \mathrm{P}=0.55$ ) or villages (Chi2 $=2.5, \mathrm{df}=2, \mathrm{P}=0.29)$.

$K d r$ genotype frequencies in the An. gambiae s.s collected resting in houses (later exposed to WHO resistance tests) were similar to the frequencies in the light trap collections. Of the $772 \mathrm{An}$. gambiae s.s tested 96.9\% (747) were homozygous for $k d r, 3.0 \%$ (24) were heterozygous and only one was wild type. None of the $A n$. arabiensis tested $(\mathrm{n}=31)$ carried the $k d r$ east mutation. No $k d r$ west mutation was found in any of the 176 An. gambiae s.s or An. arabiensis tested.

Allelic frequency was compared between An. gambiae s.s surviving or dying in the pyrethroid resistance tests. Because the $k d r$ frequency was almost fixed (98\%) there was no association between $k d r$-e allele frequency and the phenotypic resistance in WHO tests (lambdacyhalothin, permethrin, deltamethrin pvalue $=1.0$, DDT $\mathrm{p}$-value $=0.59$ )

\section{Discussion}

Anopheles gambiae s.s resistance to pyrethroids and DDT was widespread throughout the study area of Muleba district in north-western Tanzania. The frequency of the $k d r$ east approached fixation in the $A n$. gambiae s.s population but was absent in An. arabiensis. Emerging resistance to bendiocarb was observed for the first time.

There was considerable variation in the density of mosquitoes between clusters. Greater densities of mosquitoes were to be found in the south-west. It was important to test samples of Anopheles from the north-east area to investigate resistance as a possible cause of the heterogeneity in Anopheles density between the two areas. While larger samples from the north-east were desirable, this was not possible with the sampling plan and resources available. The level of mortality recorded in the resistance tests was low and never exceed $40 \%$ in 
any of the clusters (and always read against a control) regardless the sample size tested and hence considerable confidence can be placed in the overall trend in resistance.

The samples for testing were deliberately chosen from adult collections to represent natural age-structured populations. These would be a mix of young and old mosquitoes, and because the level of resistance often decreases in ageing mosquitoes $[19,20]$ the proportion surviving in the tests would have been higher had, for example, F1 adults reared from larval collections been chosen for testing instead. The disadvantage of using larval collections is the limited gene pool of the collected samples, and the possible bias in resistance frequency which is much less likely to occur with adult collections. While it is possible that the adult collection was under selection from decaying pyrethroid residues in houses, the resistance frequency would still be representative of the population.

In the resistance tests with lambdacyhalothrin on mosquitoes that were identified by PCR, 23\% of An. gambiae s.s and $100 \%$ of $A n$. arabiensis were killed overall. This is the first time that high-level pyrethroid resistance and a high frequency of the $k d r$ east mutation is reported in Tanzania. A national resistance survey conducted in 2009/2010 in 12 sentinel sites indicated that resistance is starting to be detected in other parts Tanzania but not at the levels found in Muleba district of Kagera region where IRS with lambdacyhalothrin has been intensively applied between 2006 and 2011 [10]. In the Lower Moshi agricultural zone of Kilimanjaro region, for example, An. arabiensis is the predominant species and is resistant to permethrin (13\%), attributed to elevated levels of mixed function oxidases rather than $k d r$ as the species is still fully susceptible to DDT [12], $k d r$ east has not been recorded [21] and $k d r$ west is present at very low frequency [22]. Kagera region, however, borders on neighbouring countries and resistance findings in the present study site is more similar of Uganda [23], Burundi [24] and Kenya [25] where phenotypic resistance to pyrethroids and DDT is high and $k d r$ east allele reported at a high frequency.

The high prevalence of pyrethroid resistance and high frequency of $k d r$ might be a response to selection by recurrent IRS with lambdacyhalothin since it is found nowhere else at this frequency and no other region of Tanzania has been under such intense selection pressure from pyrethroid IRS since 2006. However, it is possible that kdr present in An. gambiae in a neighbouring area spread to Muleba by migration. It is not clear whether the resistance to bendiocarb is independent of the resistance to pyrethroids or if there is a common mechanism [26] arising from pyrethroid selection since bendiocarb resistance was detected before it was used as IRS.
The implications of the pyrethroid resistance on the operational impact of vector control measures, particularly LLINs, are currently uncertain. In West Africa, in areas of high resistance, LLINs show reduced effectiveness against vector populations $[27,28]$. Control failure attributed to insecticide resistance has been observed after IRS campaigns in South Africa [2,29] and the island of Bioko [4]. While historically in some West African countries ITN/LLINs provide some protection against $k d r$ resistant Anopheles populations [30-32], that situation appears to be changing with selection of additional metabolic mechanisms $[27,28]$. In Burundi, the high frequency of $k d r$ did not lead to a loss of efficacy of IRS $[24,33]$. In western Kenya where $k d r$ in An. gambiae s.s was reaching fixation, a species shift occurred towards the more zoophilic sibling species An. arabiensis [25] despite $k d r$ being selected in An. gambiae s.s This has been attributed to the increased use of LLIN and their continued effectiveness against An. gambiae s.s [34]. Unlike western Kenya and the coast of Tanzania [35], in Muleba, An. gambiae s.s is still the predominant species of the gambiae complex despite several rounds of pyrethroid IRS and increased use of LLINs. The possible selection of supplementary resistance mechanisms in $A n$. gambiae s.s based on enhanced metabolism may explain the high prevalence of resistance and persistence of $A n$. gambiae s.s in our study area, as it has been reported in a different area of Kenya [36], but this has yet to be confirmed.

\section{Conclusions}

Anopheles gambiae s.s has developed high resistance to pyrethroids and DDT and $k d r$ frequency has almost reached fixation in north-western Tanzania. Bendiocarb resistance is also emerging in this vector. Further investigation will be needed to understand the mechanism underlying the phenotypic resistance to pyrethroids in the area and evaluate the potential operational impact of insecticide resistance in order to guide the selection of suitable insecticides and vector control interventions. Meanwhile resistance management strategies [37] should be considered and implemented to delay the expansion of insecticide resistance to other areas of Tanzania.

\section{Competing interests}

The authors declare that they have no competing interests.

\section{Authors' contributions}

NP was involved in the study design, supervised the implementation of the study and data collection, analysed data, drafted and revised the manuscript. JM was involved in data collection, helped to analyse the data, draft and revised the manuscript. RM was involved in the study design, implementation and supervision of the data collection and revised the manuscript. ReK, RoK and AW performed the real time PCR testing and revised the manuscript. PW was involved in the study design, supported the field work and revised the manuscript. IK, WK and FM were involved in the 
overall trial design, helped to draft and revised the manuscript. MR was involved in study design, interpretation of the data and revisions of the manuscript. All authors have read and approved the final version of the manuscript.

\section{Acknowledgements}

The authors express their sincere thanks to the field workers and all the PAMVERC staff at Muleba for their hard work collecting the data. We wish to thank all those who participated in the study. LSHTM, KCMC and NIMR are members of the Pan African Malaria Vector Research Consortium. This study was funded by the United States Agency for International Development under Translating Research into Action, Cooperative Agreement No. GHS-A-00-09-00015-00. This study was made possible by the support of the American people through the United States Agency for International Development (USAID). The findings of this study are the sole responsibility of LSHTM, and do not necessarily reflect the views of USAID or the United States Government.

\section{Author details}

${ }^{1}$ Department of Disease Control, London School of Hygiene and Tropical Medicine, Keppel Street, London WC1E 7HT, UK. ${ }^{2}$ Kilimanjaro Christian Medical College, Tumaini University, Moshi, Tanzania. ${ }^{3}$ National Institute for Medical Research, Amani Medical Research Centre, Muheza, Tanzania. ${ }^{4}$ Department of Infectious Disease Epidemiology, London School of Hygiene \& Tropical Medicine, Keppel Street, London, UK. ${ }^{5}$ MRC Tropical Epidemiology Group, London School of Hygiene \& Tropical Medicine, Keppel Street, London, UK

Received: 25 February 2013 Accepted: 19 April 2013

Published: 2 May 2013

\section{References}

1. WHO: World Malaria Report 2011. Switzerland: World Health Organization; 2011.

2. Hargreaves K, Hunt RH, Brooke BD, Mthembu J, Weeto MM, Awolola TS, Coetzee M: Anopheles arabiensis and An. quadriannulatus resistance to DDT in South Africa. Med Vet Entomol 2003, 17:417-422.

3. Ranson H, N'guessan R, Lines J, Moiroux N, Nkuni Z, Corbel V: Pyrethroid resistance in African anopheline mosquitoes: what are the implications for malaria control? Trends Parasitol 2011, 27:91-98.

4. Sharp BL, Ridl FC, Govender D, Kuklinski J, Kleinschmidt I: Malaria vector control by indoor residual insecticide spraying on the tropical island of Bioko, Equatorial Guinea. Malar J 2007, 6:52.

5. Martinez-Torres D, Chandre F, Williamson MS, Darriet F, Berge JB, Devonshire AL, Guillet P, Pasteur N, Pauron D: Molecular characterization of pyrethroid knockdown resistance $(\mathrm{kdr})$ in the major malaria vector Anopheles gambiae s.s. Insect Mol Biol 1998, 7:179-184.

6. Ranson H, Jensen B, Vulule JM, Wang X, Hemingway J, Collins FH: Identification of a point mutation in the voltage-gated sodium channel gene of Kenyan Anopheles gambiae associated with resistance to DDT and pyrethroids. Insect Mol Biol 2000, 9:491-497.

7. Jones CM, Liyanapathirana M, Agossa FR, Weetman D, Ranson H, Donnelly MJ, Wilding CS: Footprints of positive selection associated with a mutation (N1575Y) in the voltage-gated sodium channel of Anopheles gambiae. Proc Natl Acad Sci U S A 2012, 109:6614-6619.

8. Hanson K, Marchant T, Nathan R, Mponda H, Jones C, Bruce J, Mshinda H, Schellenberg JA: Household ownership and use of insecticide treated nets among target groups after implementation of a national voucher programme in the United Republic of Tanzania: plausibility study using three annual cross sectional household surveys. BMJ 2009, 339:b2434.

9. Bonner K, Mwita A, McElroy PD, Omari S, Mzava A, Lengeler C, Kaspar N, Nathan R, Ngegba J, Mtung'e R, Brown N: Design, implementation and evaluation of a national campaign to distribute nine million free LLINs to children under five years of age in Tanzania. Malar J 2011, 10:73.

10. Kabula B, Tungu P, Matowo J, Kitau J, Mweya C, Emidi B, Masue D, Sindato C, Malima R, Minja J, Msangi S, Njau R, Mosha F, Magesa S, Kisinza W: Susceptibility status of malaria vectors to insecticides commonly used for malaria control in Tanzania. Trop Med Int Health 2012, 17:742-750.

11. Kulkarni MA, Malima R, Mosha FW, Msangi S, Mrema E, Kabula B, Lawrence B, Kinung'hi S, Swilla J, Kisinza W, Rau ME, Miller JE, Schellenberg JA, Maxwell C, Rowland M, Magesa S, Drakeley C: Efficacy of pyrethroidtreated nets against malaria vectors and nuisance-biting mosquitoes in
Tanzania in areas with long-term insecticide-treated net use. Trop Med Int Health 2007, 12:1061-1073.

12. Matowo J, Kulkarni MA, Mosha FW, Oxborough RM, Kitau JA, Tenu F, Rowland M: Biochemical basis of permethrin resistance in Anopheles arabiensis from Lower Moshi, north-eastern Tanzania. Malar J 2010, 9:193.

13. West PA, Protopopoff N, Rowland MW, Kirby MJ, Oxborough RM, Mosha FW, Malima R, Kleinschmidt I: Evaluation of a national universal coverage campaign of long-lasting insecticidal nets in a rural district in north-west Tanzania. Malar J 2012, 11:273.

14. Gillies MT, Coetzee M: A supplement to the Anophelinae of Africa south of the Sahara (Afrotropical region). Johannesburg: South African Institute for Medical Research; 1987

15. WHO: Test procedures for insecticide resistance monitoring in malaria vectors, bio-efficacy and persistence of insecticides on treated surfaces. Geneva, Switzerland: World Health Organization; 1998.

16. Bass C, Williamson MS, Field LM: Development of a multiplex real-time PCR assay for identification of members of the Anopheles gambiae species complex. Acta Trop 2008, 107:50-53.

17. Bass C, Nikou D, Donnelly MJ, Williamson MS, Ranson H, Ball A, Vontas J, Field LM: Detection of knockdown resistance $(\mathrm{kdr})$ mutations in Anopheles gambiae: a comparison of two new high-throughput assays with existing methods. Malar J 2007, 6:111.

18. Rousset F: genepop'007: a complete re-implementation of the genepop software for Windows and Linux. Mol Ecol Resour 2008, 8:103-106.

19. Jones CM, Sanou A, Guelbeogo WM, Sagnon N, Johnson PC, Ranson H: Aging partially restores the efficacy of malaria vector control in insecticide-resistant populations of Anopheles gambiae s.l. from Burkina Faso. Malar J 2012, 11:24.

20. Rajatileka S, Burhani J, Ranson H: Mosquito age and susceptibility to insecticides. Trans R Soc Trop Med Hyg 2011, 105:247-253.

21. Mahande AM, Dusfour I, Matias JR, Kweka EJ: Knockdown resistance, rdl alleles, and the annual entomological inoculation rate of wild mosquito populations from Lower Moshi, Northern Tanzania. J Glob Infect Dis 2012, 4:114-119.

22. Kulkarni MA, Rowland M, Alifrangis M, Mosha FW, Matowo J, Malima R, Peter J, Kweka E, Lyimo I, Magesa S, Salanti A, Rau ME, Drakeley C: Occurrence of the leucine-to-phenylalanine knockdown resistance $(\mathrm{kdr})$ mutation in Anopheles arabiensis populations in Tanzania, detected by a simplified high-throughput SSOP-ELISA method. Malar J 2006, 5:56.

23. Ramphul U, Boase T, Bass C, Okedi LM, Donnelly MJ, Muller P: Insecticide resistance and its association with target-site mutations in natural populations of Anopheles gambiae from eastern Uganda. Trans R Soc Trop Med Hyg 2009, 103:1121-1126.

24. Protopopoff N, Verhaeghen K, Van BW, Roelants P, Marcotty T, Baza D, D'Alessandro U, Coosemans M: A significant increase in kdr in Anopheles gambiae is associated with an intensive vector control intervention in Burundi highlands. Trop Med Int Health 2008, 13:1479-1487.

25. Mathias DK, Ochomo E, Atieli F, Ombok M, Bayoh MN, Olang G, Muhia D, Kamau L, Vulule JM, Hamel MJ, Hawley WA, Walker ED, Gimnig JE: Spatial and temporal variation in the kdr allele L1014S in Anopheles gambiae s.s. and phenotypic variability in susceptibility to insecticides in Western Kenya. Malar J 2011, 10:10.

26. Cuamba N, Morgan JC, Irving H, Steven A, Wondji CS: High level of pyrethroid resistance in an Anopheles funestus population of the Chokwe District in Mozambique. PLoS One 2010, 5:e11010.

27. Asidi A, N'guessan R, Akogbeto M, Curtis C, Rowland M: Loss of household protection from use of insecticide-treated nets against pyrethroidresistant mosquitoes, benin. Emerg Infect Dis 2012, 18:1101-1106.

28. N'guessan R, Corbel V, Akogbeto M, Rowland M: Reduced efficacy of insecticide-treated nets and indoor residual spraying for malaria control in pyrethroid resistance area, Benin. Emerg Infect Dis 2007, 13:199-206.

29. Hargreaves K, Koekemoer LL, Brooke BD, Hunt RH, Mthembu J, Coetzee M: Anopheles funestus resistant to pyrethroid insecticides in South Africa. Med Vet Entomol 2000, 14:181-189.

30. Dabire RK, Diabate A, Baldet T, Pare-Toe L, Guiguemde RT, Ouedraogo $\mathrm{JB}$, Skovmand O: Personal protection of long lasting insecticidetreated nets in areas of Anopheles gambiae s.s. resistance to pyrethroids. Malar J 2006, 5:12.

31. Darriet F, N'guessan R, Koffi AA, Konan L, Doannio JM, Chandre F: Carnevale $\mathrm{P}$ : [Impact of pyrethrin resistance on the efficacity of impregnated mosquito nets in the prevention of malaria: results of tests in 
experimental cases with deltamethrin SC](in French). Bull Soc Pathol Exot 2000, 93:131-134.

32. Henry MC, Assi SB, Rogier C, Dossou-Yovo J, Chandre F, Guillet P, Carnevale P: Protective efficacy of lambda-cyhalothrin treated nets in Anopheles gambiae pyrethroid resistance areas of Cote d'Ivoire. Am J Trop Med Hyg 2005, 73:859-864.

33. Protopopoff N, Van BW, Marcotty T, Van HM, Maes P, Baza D, D'Alessandro $U$, Coosemans M: Spatial targeted vector control in the highlands of Burundi and its impact on malaria transmission. Malar J 2007, 6:158.

34. Bayoh MN, Mathias DK, Odiere MR, Mutuku FM, Kamau L, Gimnig JE, Vulule JM, Hawley WA, Hamel MJ, Walker ED: Anopheles gambiae: historical population decline associated with regional distribution of insecticidetreated bed nets in western Nyanza Province, Kenya. Malar J 2010, 9:62.

35. Kitau J, Oxborough RM, Tungu PK, Matowo J, Malima RC, Magesa SM, Bruce J, Mosha FW, Rowland MW: Species shifts in the Anopheles gambiae complex: do LLINs successfully control Anopheles arabiensis? PLoS One 2012, 7:e31481.

36. Ochomo E, Bayoh MN, Brogdon WG, Gimnig JE, Ouma C, Vulule JM, Walker ED: Pyrethroid resistance in Anopheles gambiae s.s. and Anopheles arabiensis in western Kenya: phenotypic, metabolic and target site characterizations of three populations. Med Vet Entomol 2012. doi:10.1111/ j.1365-2915.2012.01039.x.

37. WHO: The technical basis for coordinated action against insecticide resistance: preserving the effectiveness of modern malaria vector control. Geneva, Switzerland: World Health Organization; 2010.

doi:10.1186/1475-2875-12-149

Cite this article as: Protopopoff et al:: High level of resistance in the mosquito Anopheles gambiae to pyrethroid insecticides and reduced susceptibility to bendiocarb in north-western Tanzania.

Malaria Journal 2013 12:149.

\section{Submit your next manuscript to BioMed Central and take full advantage of:}

- Convenient online submission

- Thorough peer review

- No space constraints or color figure charges

- Immediate publication on acceptance

- Inclusion in PubMed, CAS, Scopus and Google Scholar

- Research which is freely available for redistribution 